\title{
Motivos clásicos en el teatro español de los Siglos de Oro
}

\author{
Todas las cosas se mutan, nada perece: erra y de allí \\ para acá viene, de aqui para allá, y \\ cualesquiera ocupa miembros el espíritu... \\ P. Ovidio Nasón, Las Metamorfosis
}

$(15.165-171)$

Palabras clave: literatura grecorromana, literatura española, Siglos de Oro, pervivencia y recepción, motivos clásicos.

\section{Introducción}

El objetivo del siguiente trabajo es delimitar a partir de un análisis comparativo la relación entre los motivos renacentistas y los barrocos dentro del marco del teatro español de los Siglos de Oro, elaborando así el corpus de los motivos clásicos fundamentales empleados, entre otros, por los autores españoles de los Siglos de Oro. El foco de nuestra investigación han sido los siguientes temas:

- la pervivencia de los motivos clásicos grecorromanos en los Siglos de Oro, - las obras clásicas que representan sus respectivas fuentes,

- los autores que emplean los motivos clásicos,

- la posible tipología de los motivos, empleados por ciertos autores,

- la existencia de las transformaciones (o la limitación de los autores en la simple imitación),

- el papel intermediario del teatro renacentista italiano,

- las diferencias entre el Renacimiento y Barroco en cuanto a la cantidad y el contenido de los motivos. 
El material fundamental que hemos tratado son las obras conservadas de teatro grecorromano, las obras de Esquilo, Eurípides y Sófocles, 21 comedias de Plauto, seis comedias de Terencio, las tragedias de Séneca, es decir, Agamemnon, Hercules furens, Hercules oetaeus, Medea, Oedipus, Phaedra, Phoenissae, Thyestes, Troades, Octavia y las obras de los principales dramaturgos del Renacimiento y Barroco español, centrándonos en las comedias, las tragedias y los autos sacramentales barrocos. A causa de la amplia producción literaria -solo el supuesto corpus auténtico de Lope de Vega abarca 426 comedias- hemos analizado todas las obras o la parte de las obras de los dramaturgos más destacados: los textos dramáticos de Juan del Encina, Lucas Fernández, Bartolomé Torres Naharro, Gil Vicente, Lope de Rueda, la tragedia La Numancia de Miguel de Cervantes, las comedias mitológicas y algunas históricas de Lope de Vega, los autos sacramentales mitológicos de Calderón de la Barca y su auto sacramental filosófico-teológico El gran teatro del mundo.

\section{Panorama del teatro español del siglo XVI}

La creación literaria en España en la primera mitad del siglo XVI estuvo marcada por la búsqueda de nuevos caminos y modelos de expresión. Uno de los rasgos característicos de la producción de entonces era la oscilación entre la expresión, tradicional y la nueva, la italiana. Los contactos con la cultura italiana eran físicos, ya que es bien sabido que algunos autores españoles viven en Italia o viajan por ella. Algunos autores españoles destacados, entre ellos Juan del Encina y Bartolomé Torres Naharro, pasan al menos una parte de su vida allí o mantienen contactos con los portadores de los impulsos culturales del renacimiento italiano en España. Sin embargo, el papel intermediario del teatro italiano en cuanto a los motivos hasta la segunda mitad del siglo XVI es menos notable, ya que el desarrollo del teatro italiano y del español se basa en dos conceptos diferentes. La creación teatral italiana está estrechamente ligada a la herencia clásica, mientras que la española lo está a los elementos populares (Arróniz 1969: 11).

No obstante, el teatro clásico romano -aquí hay que subrayar sobre todo la contribución de Plauto, no tanto de Terencio- marcó la historia, al menos en parte, de la creación dramática española, a pesar de que el modelo de la fabula palliata no es el que prevaleció y triunfó. Los motivos del teatro clásico, sobre todo del romano, entraron en el teatro español por la puerta lateral, aunque decisiva para los alumnos de los colegios jesuitas y estudiantes universitarios, teniendo en cuenta su posible dedicación al teatro y su producción posterior. En las universidades y en los colegios jesuitas las representaciones de las 
comedias romanas formaban parte del currículo obligatorio de la retórica y algunos profesores como, por ejemplo Juan de Mal Lara, Francisco Sánchez de las Brozas, Fernán Pérez de Oliva y Pedro Simón Abril tradujeron las obras latinas o escribieron las propias siguiendo el modelo de Plauto y Terencio.

Según Highet (1985: 120-123), en el siglo XVI se traducen al español las siguientes obras griegas o latinas:

1. dramática griega:

- Sófocles, Electra - La venganza de Agamenón, traductor Fernán Pérez de Oliva, alrededor del año 1525;

- Eurípides, Hécuba - Hécuba triste, traductor Fernán Pérez de Oliva, 1528;

- Aristófanes, Plutos (La riqueza), traductor Pedro Simón Abril, 1577.

2. dramática latina:

- Plauto, Ampbitruo (Anfitruón), traductor Francisco López de Villalobos, 1515

- Terencio, Opera omnia, traductor Pedro Simón Abril, 1577, edición bilingüe;

- Séneca, todas las tragedias están traducidas al español ya en el siglo XV y al catalán incluso antes, ya en el año 1400, traductor Antonio Vilaragut (Medea, Tiestes, Las troyanas).

Para numerosos dramaturgos españoles el encuentro con el teatro universitario o los textos teatrales en los colegios jesuitas fue el momento clave que los marcó y por el cual a continuación introdujeron en su obra los temas y motivos clásicos redirigiéndolos hacia lo divino, como por ejemplo Lope de Vega y Calderón de la Barca, dentro del marco de los dramas religiosos que surgieron también en el contexto español.

Al investigar y analizar los motivos clásicos hemos comprobado que en el teatro español de los Siglos de Oro podemos encontrar todas las formas de la recepción de los motivos clásicos:

- la más simple directa o abierta (las citas directas de un autor clásico; la cita puede ser más o menos completa o puede ser una clara alusión),

- semidirecta o velada (no hay mención explícita de un autor clásico, lo que se menciona son ciertos elementos clásicos (personas, lugares, circunstancias históricas)),

- indirecta o cubierta (no hay ninguna señal clara de que se trate de una intervención literaria hacia la Antigüedad o la imitación de algún fragmento 
o motivo literarios; aquí pueden aparecer también los siguientes niveles, la aemulatio o la variatio).

Los motivos tomados de la Antigüedad sin transformaciones o innovaciones y usados en el Renacimiento o el Barroco son prácticamente inexistentes. Si corresponden por completo a sus antecedentes clásicos, normalmente se trata solo de la mención o el uso de un motivo secundario para ilustrar una situación semejante sin profundizar o entretejer el motivo en la estructura sustentadora de la obra dramática.

\section{Motivos clásicos en el mundo dramático de Juan del Encina, Lucas Fernández, Bartolomé Torres Naharro, Gil Vicente y Lope de Rueda}

En la obra de Juan del Encina la influencia más notable es la de Virgilio y de sus Bucólicas, un poco menos impacto tiene su Eneida. Del Encina fue también traductor de la obra de Virgilio al castellano, lo cual dejó mucha huella en los rasgos característicos de su propia obra. Además, los puntos en común entre Del Encina y Virgilio van más allá del ámbito literario de los motivos, puesto que Del Encina recurre a la forma bucólica de las églogas y mantiene como protagonistas a los pastores. En relación con este hecho tratamos de aclarar las razones de la pervivencia de las églogas y de la transformación en la forma, de la lírica a la dramática. Se puede suponer que además del carácter animado de las églogas de Virgilio la incitaron algunos comentarios clásicos y las noticias de puestas en escena ya en los tiempos en que todavía vivió Virgilio, es decir, en la época de Cicerón (la observación en el comentario de Servio, la anotación en la Vita Vergili de Donato y la mención en el Dialogus de oratoribus de Tácito):

- «Dicitur (sc. ecloga) autem ingenti favore a Vergilio esse recitata, adeo, ut, cum eam postea Cytheris cantasset in theatro, [...] stupefactus Cicero, cuius esset, requiret [...]» (Servio, ecl. 6. 11)

- «Bucolica eo successu edidit, ut in scaena quoque per cantores crebro pronuntiarentur.» (Vit. Verg. 26)

- «Testes Augusti epistulae, testis ipse populus, qui auditis in theatro Vergilii versibus surrexit universus et forte praesentem spectantemque Vergilium veneratus est sic quasi Augustum.» (Dial. 13.2.)

Del Encina recurre en su obra también a los motivos procedentes de los poetas elegíacos (el motivo de la esclavitud del amor, o sea, servitium amoris y el 
motivo de la fuerza destructiva del amor), cuyas fuentes son las obras de Ovidio Ars amatoria y Remedia amoris (el motivo de «dos amantes y más»). Muy destacado es el motivo mitológico del Amor cruel, presente no solo en la mitología clásica, sino también en la lírica y elegía romana. Además, hay algunos motivos secundarios cuyo referente clásico más probable son las Metamorfosis de Ovidio (motivo de Píramo y Tisbe, de Hero y Leandro, de Mercurio, del río Lete) que llegaron a ser la fuente básica y el manual mitológico de los autores del Barroco.

En la obra de Del Encina se nota también la herencia de la fabula palliata Romana. Encina conserva los motivos del prólogo y del «esclavo astuto». El aspecto exterior de este cambia. El esclavo se desprende de su imagen anacrónica, asume el papel de pastor conservando los rasgos característicos del servus Romanus. La mayoría de los motivos en esta época se transmite a través de la tradición literaria, pero podemos suponer que al menos uno (el motivo del epitafio formulado como alocución del difunto al transeúnte), pasa al mundo dramático de Del Encina desde el mundo extraliterario, o sea, desde el conocimiento general de la Antigüedad por parte del autor, profundamente marcado por ella.

La obra dramática de Lucas Fernández no está tan impregnada por los motivos líricos de Virgilio, sin embargo, como motivo secundario, casi como simple mención, se conserva el de Dido, ya usado antes por Juan del Encina. Por primera vez en la literatura española aparece -aunque de una forma más rudimentaria - el motivo del soldado fanfarrón, creado en la literatura romana por Plauto en Miles gloriosus, que, después, en la obra de Torres Naharro adopta una forma más elaborada. Cabe resaltar que no se trata de una caricatura destacada de la fanfarronería y la jactancia como en Plauto, donde este defecto del soldado desempeña el papel del spiritus movens de la comicidad verbal del mencionado drama, sino una representación bastante neutra del personaje del soldado. La fanfarronería tampoco es el motivo central de la farsa. Las escenas consecutivas son más bien imágenes anecdóticas y no secuencias de una comedia construida con premeditación, a través de la cual se hace visible la imagen aguda del carácter del protagonista. Sin embargo, Fernández en las réplicas del soldado esboza los rasgos fundamentales de la jactancia y del engreimiento. En la obra de Fernández está presente también el motivo de Amor, de Dafne, usado después en el Barroco por Lope de Vega en una de sus comedias mitológicas, y el motivo de Lucrecia, que procede de la historia semilegendaria de Roma y carece de una tradición de elaboraciones literarias y artísticas en general. 
Bartolomé Torres Naharro sigue usando y desarrollando «el aparato introductorio» clásico. También en la Antigüedad tiene sus raíces el motivo de «valete et plaudite» que, como en Plauto, aparece en los epílogos de sus obras. Podemos presentir los ecos de Plauto también en la figura del Capitán de la Soldadesca; clásicos son también los motivos de la anagnórisis, un recurso muy frecuente en la obra plautina para resolver el enredo, presente generalmente ya en la historia preliminar. El motivo de tres reconocidos médicos de la Antigüedad, Asclepio, su hijo Polidario y Galeno en la Aquilana no procede de la tradición literaria, sino que lo utiliza por primera vez Torres Naharro. Otra innovación de Torres Naharro que no encontramos en los autores anteriores es el motivo del «Beatus ille...», relacionado con el motivo del locus amoenus que aparece en la Jacinta. Además de Teócrito, el referente clásico para la literatura europea es, sobre todo, Horacio. La razón de su aparición en la Antigüedad y su reaparición son las circunstancias históricas y los rasgos característicos de la civilización (el desarrollo de las metrópolis, la sobrepoblación de las ciudades, el proceso de vaciamiento del campo, la aparición de la nostalgia y el anhelo de una vida retirada...).

Los rasgos característicos que muestran el conocimiento de la comedia romana y los fundamentos clásicos del concepto dramático de Naharro son sobre todo los siguientes:

- la estructura externa, es decir, la división en prólogo, cinco actos (jornadas) y epílogo,

- los nombres de algunos protagonistas en algunas comedias (Himeneo, Febea, Boreas en la Himenee, Orfea en la Serafina, Lucrecia en la Tinelaria, Esculapio, Polidario, Galieno en la Aquilana, Ptolomeo, la Fama en la Trofea),

- la caracterización de los personajes,

- las ingeniosas intrigas, típicas para el mundo del teatro plautino, y las relaciones intrigantes entre los personajes,

- el uso del aparté, con frecuencia usado por Plauto, acentuando así la comicidad verbal y estableciendo una relación más estrecha entre la acción en el escenario y el público (nótese que a través de la continua comunicación simpática de los actores con los espectadores Plauto, no solo en el prólogo, quiere obtener o consolidar la captatio benevolentiae),

- la agilidad lingüística y el dominio de registros muy variados,

- el uso de citas de la literatura romana y la paráfrasis de estas.

En el teatro castellano de Gil Vicente las menciones de los dioses o héroes clásicos (Cástor y Pólux, Latona, Diana, Apolo, Juno, Baco, Himeneo, Eneas) 
y un elemento cultural (la fiesta Februa) tienen una marcada función decorativa. Incluso el fragmento donde habla Júpiter de ninguna manera procede de la herencia clásica. Se puede constatar que el uso de los elementos grecorromanos es una mera enumeración de carácter erudito. Más que los motivos, la presencia del mundo antiguo en la obra de Gil Vicente Auto de los cuatro tiempos podría ser considerada como meras reminiscencias decorativas, puesto que no están estrechamente ligadas con la estructura interna de la obra. Se trata de un motivo meramente decorativo, «altisonante y erudito» (Zimic 2003: 137). La figura de Júpiter está presente también en la Tragicomédia Chamada Côrtes de Júpiter, escrita en portugués. Además, de carácter clásico están también dotadas dos de sus obras portuguesas, la Tragicomédia de Frágua de Amor y la Tragicomédia Chamada Templo de Apolo.

A mediados del siglo XVI, cuando con Lope de Rueda empieza el desarrollo del teatro popular, el interés se centra en el enredo dramático animado, cuyo antecedente podríamos buscarlo en la fabula de Plauto. Lope de Rueda recurre también al tesoro mitológico y usa el motivo de Medea, uno de los motivos literarios más recurrentes y complejos que vuelve a ser utilizado en el Barroco en las comedias mitológicas de Lope de Vega y en uno de los autos sacramentales de Calderón de la Barca. El motivo de Neptuno y Eolo no son tan frecuentes y no suelen desarrollarse en el motivo central de la obra en la que aparecen.

\section{La Numancia de Miguel de Cervantes}

Se puede suponer que también Miguel de Cervantes conoció bastante bien a los autores grecorromanos, al menos los que formaban parte del canon clásico, como entre otros Ovidio y Virgilio. Se familiarizó con las obras clásicas durante su formación con los jesuitas y durante su estancia en Italia (1569-1575). Con el uso de los motivos, argumentos y temas a lo largo de toda su creación literaria demostró una y otra vez que el mundo antiguo grecorromano no le era un mundo ajeno. En el capítulo 11 de la primera parte del Quijote, por ejemplo, le revela al lector la imagen completa de la edad de oro clásica, muy parecida a la que (re)creó Ovidio en sus Metamorfosis al escribir sobre las edades humanas:

Dichosa edad y siglos dichosos aquellos a quien los antiguos pusieron nombre de dorados, y no porque en ellos el oro, que en esta nuestra edad de hierro tanto se estima, se alcanzase en aquella venturosa sin fatiga alguna, sino porque entonces los 
que en ella vivían ignoraban estas dos palabras de tuyo y mío. Eran en aquella santa edad todas las cosas comunes: a nadie le era necesario para alcanzar su ordinario sustento tomar otro trabajo que alzar la mano y alcanzarle de las robustas encinas, que liberalmente les estaban convidando con su dulce y sazonado fruto. (Cervantes 2004: 89)

Según señala Aurora Egido (2013: 18), «cuando Cervantes utilizaba palabras o frases de autores concretos, sin nombrarlos, apeló numerosas veces a la connivencia de los lectores o a la de los espectadores, que se sentirían felices al reconocerlas.» Se trata de una especie de acuerdo entre el autor y el público, un juego que consistía en tratar de identificar elementos que formaban parte de la obra y un elemento adicional de diversión teniendo en cuenta de que el público barroco de los espectáculos polifacéticos -aquí nos referimos al teatro, al espectáculo teatral- era muy heterogéneo.

Los motivos en La Numancia por lo general no son mitológicos, a pesar de que en los Siglos de Oro la mitología clásica representa una fuente incesable de los motivos, elementos constitutivos de la pervivencia de la literatura clásica en la literatura posterior. Cabe hacer hincapié sobre la variedad y particularidad de los motivos y, además, sobre el hecho de que todos estén impregnados de una profunda nota humanística, presente en la obra de Cervantes sobre todo en su actitud de constante defensa de la libertad y la dignidad humanas (Abellán: 1996: 240).

Cervantes, en La Numancia, emplea muchos motivos clásicos, procedentes de diferentes géneros clásicos (la tragedia griega, la lírica, la tragedia romana, los tratados de filosofía estoica). Entre ellos los más representantivos son los siguientes:

- el motivo del sacrificio colectivo (el referente clásico son Los Persas de Esquilo),

- el motivo del destino de una ciudad heroica,

- el motivo de la predicción de la grandeza de una nación (el referente es la Eneida de Virgilio),

- el motivo de la libertad y de la dignidad humana (estos dos motivos están estrechamente ligados (la fuente clásica es Epícteto y sus Diatribas o Enchiridion, muy pronto a disposición del público español a través de varias traducciones, entre otros la de Sánchez de las Brozas de 1612)

- «pro patria mori» / morir por la patria (la fuente clásica es Horacio, Odas 3,2), 
- de la invocación del muerto y su resucitación temporal, (las fuentes son la tragedia Los Persas de Esquilo y el texto dramático Edipo de Séneca),

- de los sacrificios y los agüeros, es decir, los pronósticos, favorables o adversos, formados por señales (el Edipo de Séneca y las Metamorfosis de Ovidio (Libro X, concretamente el episodio de las bodas de Orfeo y Eurídice, el agüero en forma de fuego que no quiere encenderse).

\section{Mundo mitológico de Lope de Vega}

Lope de Vega crea en sus comedias de tema mitológico un mundo y un escenario sui generis que actualiza los mitos clásicos. Lope de Vega forma un escenario lleno de imágenes mitológicas añadiendo a los protagonistas fundamentales de la fábula clásica tanto personajes secundarios que provienen de otros mitos no tan recurrentes como protagonistas principales de las historias comúnmente conocidas. Toma como base un mito clásico refinándolo con numerosas innovaciones propias y ya existentes o, según afirma Zamora Vicente (1961: 211):

En ese teatro está todo, lo antiguo y lo moderno, lo nacional y lo extranjero; Lope supo fundir en una unidad admirable todos los elementos, formas o procedimientos que en las letras españolas corrían antes de él, ya maduros, ya embrionarios. Esquilmó al servicio de su comedia lo mismo lo sagrado (narraciones bíblicas, leyendas hagiográficas) que lo profano, culto y artificioso (lo pastoril, lo caballeresco). Supo vestir todo ese mundo libresco con elementos extraídos de la realidad inmediata, especialmente con los de tradición popular (cantarcillos, refranes, supersticiones); conoció todo el arsenal literario que su época tenía en circulación: historias antiguas (Herodoto, Ovidio, Horacio) y renacentistas italianas (Boccaccio, Bandello, Giraldi Cintio). Utilizó de manera asombrosa las Crónicas españolas y el Romancero épico. Manejó y adaptó los hallazgos dramáticos y cómicos de La Celestina y supo apreciar su trascendencia humana y artística; llegan a su voz, transformados en aliento nuevo, los recuerdos de Juan del Encina, de Torres Naharro, de Lope de Rueda. Aprovecha y encamina definitivamente los atisbos de Juan de la Cueva en lo que suponía acercarse a la tradición oral. Todo ello fue seleccionado, meditado e incorporado a su más honda vena y recreado en el inmenso caudal de sus comedias. 
La parte de la decoración externa la forman también las menciones de los personajes mitológicos y alusiones a ellas y los acontecimientos en los que figuran. Las mencionadas reminiscencias clásicas funcionan como «la ventana» que abre camino a las dimensiones nuevas del motivo clásico original. Este procedimiento creativo refleja una de las aficiones fundamentales del Barroco, la reduplicación de las estructuras que podríamos comparar con el lenguaje pictórico de Velázquez y su procedimiento de abrir nuevas dimensiones del cuadro y doblar los mundos en, por ejemplo, Las meninas. La mención de Lope de Vega pudo evocar en un espectador -dependiendo de su formación, su conocimiento del motivo y la difusión de este- un episodio entero que se había ido construyendo alrededor del motivo que el dramaturgo insertó en la estructura fundamental del argumento.

La característica principal de las comedias mitológicas de Lope de Vega es la numerosidad de los personajes y la técnica de mezclar y contaminar diferentes mitos al nivel de los personajes. El dramaturgo en sus obras combina los motivos con otros o ciertos rasgos de otros, como en la mitología clásica se entrelazan las historias mitológicas pasando o transformándose una en otra o a veces discurriendo paralelamente una junto a otra. Su técnica a veces vuelve a asemejarse al procedimiento de Velázquez, al incorporar los motivos mitológicos en la escena de género, tomada del mundo barroco (La fragua de Vulcano o Las bilanderas, por ejemplo). Lope de Vega suele emplear fábulas de tema amoroso (Orfeo y Eurídice, Céfalo y Procris, Jasón y Medea, Teseo y Ariadna, Apolo y Dafne, entre otros), lo que constituye una de las constantes en sus obras. A veces subraya el motivo amoroso añadiéndole una historia de amor mitológico o bucólico no existente en la mitología clásica. Sus comedias mitológicas están pobladas de menciones y reminiscencias clásicas. 


\section{Corpus esquemático de los motivos clásicos en el teatro español de los Siglos de Oro}

\section{Motivos clásicos en el teatro renacentista español}

\begin{tabular}{|c|c|c|}
\hline MOTIVO & OBRA & AUTOR \\
\hline Motivo del amor infeliz & $\begin{array}{l}\text { Égloga de Fileno, Zambardo y } \\
\text { Cardonio }\end{array}$ & Juan del Encina \\
\hline Motivo del «servitium amoris» & $\begin{array}{l}\text { Égloga de Fileno, Zambardo y } \\
\text { Cardonio; } \\
\text { Égloga de Plácida y Vitoriano }\end{array}$ & Juan del Encina \\
\hline $\begin{array}{l}\text { Motivo de la representación } \\
\text { negativa de las cualidades de la } \\
\text { muchacha }\end{array}$ & $\begin{array}{l}\text { Égloga de Fileno, Zambardo y } \\
\text { Cardonio }\end{array}$ & Juan del Encina \\
\hline $\begin{array}{l}\text { Motivo del suicidio cometido } \\
\text { por amor (infeliz, no correspon- } \\
\text { dido) o la fuerza destructiva del } \\
\text { amor }\end{array}$ & $\begin{array}{l}\text { Égloga de Fileno, Zambardo y } \\
\text { Cardonio; } \\
\text { Égloga de Plácida y Vitoriano }\end{array}$ & Juan del Encina \\
\hline $\begin{array}{l}\text { Motivo del epitafio formulado } \\
\text { como la alocución del difunto al } \\
\text { transeúnte }\end{array}$ & $\begin{array}{l}\text { Égloga de Fileno, Zambardo y } \\
\text { Cardonio }\end{array}$ & Juan del Encina \\
\hline Motivo de «dos amantes o más» & Égloga de Plácida y Vitoriano & Juan del Encina \\
\hline $\begin{array}{l}\text { Motivo del puñal/arma que } \\
\text { antes pertenecía al amante }\end{array}$ & Égloga de Plácida y Vitoriano & Juan del Encina \\
\hline Motivo de Píramo y Tisbe & Égloga de Plácida y Vitoriano & Juan del Encina \\
\hline Motivo de Hero y Leandro & Égloga de Plácida y Vitoriano & Juan del Encina \\
\hline $\begin{array}{l}\text { Motivo de Mercurio, acom- } \\
\text { pañante de las almas }\end{array}$ & Égloga de Plácida y Vitoriano & Juan del Encina \\
\hline $\begin{array}{l}\text { Motivo de la resucitación de la } \\
\text { muchacha amada }\end{array}$ & Égloga de Plácida y Vitoriano & Juan del Encina \\
\hline Motivo del río del olvido & Égloga de Plácida y Vitoriano & Juan del Encina \\
\hline $\begin{array}{l}\text { Motivo del todopoderoso y } \\
\text { cruel Amor }\end{array}$ & $\begin{array}{l}\text { Representación sobre el poder del } \\
\text { Amor; } \\
\text { Égloga de Mingo, Gil y Pascuala; } \\
\text { Égloga de Fileno, Zambardo y } \\
\text { Cardonio; } \\
\text { Égloga de Cristino y Febea; } \\
\text { Égloga de Plácida y Vitoriano }\end{array}$ & Juan del Encina \\
\hline Motivo del «esclavo astuto» & Égloga de Plácida y Vitoriano & Juan del Encina \\
\hline Motivo del Prólogo & Égloga de Plácida y Vitoriano & Juan del Encina \\
\hline Motivo de Dido & $\begin{array}{l}\text { Farsa o cuasi comedia de una } \\
\text { Doncella, un Pastor y un Galán }\end{array}$ & Lucas Fernández \\
\hline
\end{tabular}




\begin{tabular}{|c|c|c|}
\hline MOTIVO & OBRA & AUTOR \\
\hline Motivo de Lucrecia & $\begin{array}{l}\text { Farsa o cuasi comedia de una } \\
\text { Doncella, un Pastor y un Galán }\end{array}$ & Lucas Fernández \\
\hline Motivo de Dafne & $\begin{array}{l}\text { Farsa o cuasi comedia de una } \\
\text { Doncella, un Pastor y un Galán }\end{array}$ & Lucas Fernández \\
\hline Motivo de Amor & $\begin{array}{l}\text { Farsa o cuasi comedia de Prabos } \\
\text { y Antona o Farsa o cuasi comedia } \\
\text { en la qual se introduzen quatro } \\
\text { personas }\end{array}$ & Lucas Fernández \\
\hline $\begin{array}{l}\text { Motivo del soldado fanfarrón o } \\
\text { «miles gloriosus» }\end{array}$ & $\begin{array}{l}\text { Farsa o cuasi comedia de Prabos } \\
\text { y Antona o Farsa o cuasi comedia } \\
\text { en la qual se introduzen quatro } \\
\text { personas; } \\
\text { Soldadesca }\end{array}$ & $\begin{array}{l}\text { Lucas Fernández } \\
\text { Bartolomé Torres } \\
\text { Naharro }\end{array}$ \\
\hline Motivo de Apolo & Trofea & $\begin{array}{l}\text { Bartolomé Torres } \\
\text { Naharro }\end{array}$ \\
\hline Motivo de la Fama & Trofea & $\begin{array}{l}\text { Bartolomé Torres } \\
\text { Naharro }\end{array}$ \\
\hline $\begin{array}{l}\text { Motivo del «Beatus ille...»y } \\
\text { «locus amoenus» }\end{array}$ & Jacinta & $\begin{array}{l}\text { Bartolomé Torres } \\
\text { Naharro }\end{array}$ \\
\hline Motivo de «valete et plaudite» & $\begin{array}{l}\text { Serafina; } \\
\text { Tinelaria; } \\
\text { Trofea }\end{array}$ & $\begin{array}{l}\text { Bartolomé Torres } \\
\text { Naharro }\end{array}$ \\
\hline Motivo de los médicos & Aquilana & $\begin{array}{l}\text { Bartolomé Torres } \\
\text { Naharro }\end{array}$ \\
\hline Motivo de la anagnórisis & $\begin{array}{l}\text { Calamita; } \\
\text { Aquilana }\end{array}$ & $\begin{array}{l}\text { Bartolomé Torres } \\
\text { Naharro }\end{array}$ \\
\hline Motivo de Júpiter & Auto de los cuatro tiempos & Gil Vicente \\
\hline Motivo de Medea & Armelina & Lope de Rueda \\
\hline Motivo de Neptuno & Armelina & Lope de Rueda \\
\hline Motivo de Eolo & Armelina & Lope de Rueda \\
\hline $\begin{array}{l}\text { Motivo de Minotauro, Pasifae, } \\
\text { Teseo y Ariadna }\end{array}$ & Armelina & Lope ed Rueda \\
\hline Motivo de los gemelos & $\begin{array}{l}\text { Armelina; } \\
\text { Los engañados } \\
\text { Medora }\end{array}$ & Lope de Rueda \\
\hline Motivo del disfraz & Armelina & Lope de Rueda \\
\hline
\end{tabular}




\section{Motivos clásicos en el teatro barroco español}

\begin{tabular}{|c|c|c|}
\hline MOTIVO & OBRA & AUTOR \\
\hline $\begin{array}{l}\text { Motivo del asedio de la Numan- } \\
\text { cia }\end{array}$ & Numancia & $\begin{array}{l}\text { Miguel de Cer- } \\
\text { vantes }\end{array}$ \\
\hline Motivo del sacrificio colectivo & Numancia & $\begin{array}{l}\text { Miguel de Cer- } \\
\text { vantes }\end{array}$ \\
\hline $\begin{array}{l}\text { Motivo del destino de una ciu- } \\
\text { dad heroica o rebelde y de la } \\
\text { conciencia del destino humano } \\
\text { común }\end{array}$ & Numancia & $\begin{array}{l}\text { Miguel de Cer- } \\
\text { vantes }\end{array}$ \\
\hline $\begin{array}{l}\text { El motivo de la predicción de la } \\
\text { grandeza de una nación }\end{array}$ & Numancia & $\begin{array}{l}\text { Miguel de Cer- } \\
\text { vantes }\end{array}$ \\
\hline $\begin{array}{l}\text { Motivo de la libertad y la digni- } \\
\text { dad humana }\end{array}$ & Numancia & $\begin{array}{l}\text { Miguel de Cer- } \\
\text { vantes }\end{array}$ \\
\hline Motivo «pro patria mori» & Numancia & $\begin{array}{l}\text { Miguel de Cer- } \\
\text { vantes }\end{array}$ \\
\hline $\begin{array}{l}\text { Motivo de la invocación del } \\
\text { muerto y su resucitación tem- } \\
\text { poral }\end{array}$ & Numancia & $\begin{array}{l}\text { Miguel de Cer- } \\
\text { vantes }\end{array}$ \\
\hline $\begin{array}{l}\text { Motivo del sacrificio y de los } \\
\text { agüeros }\end{array}$ & Numancia & $\begin{array}{l}\text { Miguel de Cer- } \\
\text { vantes }\end{array}$ \\
\hline Motivo de Adonis y Venus & Adonis y Venus & Lope de Vega \\
\hline Motivo de las Amazonas & Las mujeres sin hombres & Lope de Vega \\
\hline Motivo de Perseo & El Perseo & Lope de Vega \\
\hline $\begin{array}{l}\text { Motivo del laberinto de Creta } \\
\text { (Minos, Pasifae, Minotauro, Dé- } \\
\text { dalo, Ícaro, Teseo y Ariadna) }\end{array}$ & $\begin{array}{l}\text { El laberinto de Creta } \\
\text { El laberinto de Creta }\end{array}$ & $\begin{array}{l}\text { Lope de Vega } \\
\text { Tirso de Molina }\end{array}$ \\
\hline Motivo del Anfitrión & El laberinto de Creta & Lope de Vega \\
\hline $\begin{array}{l}\text { Motivo de la inconstancia de las } \\
\text { mujeres }\end{array}$ & El laberinto de Creta & Lope de Vega \\
\hline Motivo del vellocino de oro & El vellocino de Oro & Lope de Vega \\
\hline Motivo de Orfeo y Eurídice & $\begin{array}{l}\text { El marido más firme; } \\
\text { El divino Orfeo }\end{array}$ & $\begin{array}{l}\text { Lope de Vega } \\
\text { Calderón de la } \\
\text { Barca }\end{array}$ \\
\hline Motivo de Céfalo y Procris & La bella Aurora & Lope de Vega \\
\hline Motivo de Dafne y Apolo & El Amor enamorado & Lope de Vega \\
\hline $\begin{array}{l}\text { Motivo del Pitón, matado por } \\
\text { Apolo }\end{array}$ & $\begin{array}{l}\text { El Amor enamorado; } \\
\text { El verdadero dios Pan }\end{array}$ & $\begin{array}{l}\text { Lope de Vega } \\
\text { Calderón de la } \\
\text { Barca }\end{array}$ \\
\hline
\end{tabular}




\begin{tabular}{|c|c|c|}
\hline MOTIVO & OBRA & AUTOR \\
\hline Motivo del incendio de Roma & Roma abrasada & Lope de Vega \\
\hline $\begin{array}{l}\text { Motivo de los Horacios y Curia- } \\
\text { cios }\end{array}$ & El honrado hermano & Lope de Vega \\
\hline Motivo de Androclo y el león & El esclavo de Roma & Lope de Vega \\
\hline Motivo de Psique v Cupido & $\begin{array}{l}\text { Psiquis y Cupido para Toledo } \\
\text { Psiquis y Cupido para Madrid }\end{array}$ & $\begin{array}{l}\text { Calderón de la } \\
\text { Barca }\end{array}$ \\
\hline Motivo de Odiseo y Circe & Los encantos de la culpa & $\begin{array}{l}\text { Calderón de la } \\
\text { Barca }\end{array}$ \\
\hline Motivo de Orfeo & El divino Orfeo & $\begin{array}{l}\text { Calderón de la } \\
\text { Barca }\end{array}$ \\
\hline Motivo de Jasón & El divino Jasón & $\begin{array}{l}\text { Calderón de la } \\
\text { Barca }\end{array}$ \\
\hline Motivo de Parnaso & El sacro Parnaso & $\begin{array}{l}\text { Calderón de la } \\
\text { Barca }\end{array}$ \\
\hline Motivo de Pan & El verdadero dios Pan & $\begin{array}{l}\text { Calderón de la } \\
\text { Barca }\end{array}$ \\
\hline Motivo de Teseo y Minotauro & El laberinto del mundo & $\begin{array}{l}\text { Calderón de la } \\
\text { Barca }\end{array}$ \\
\hline Motivo de Andrómeda y Perseo & Andrómeda y Perseo & $\begin{array}{l}\text { Calderón de la } \\
\text { Barca }\end{array}$ \\
\hline $\begin{array}{l}\text { Motivo de la vida como teatro o } \\
\text { representación teatral }\end{array}$ & $\begin{array}{l}\text { El gran teatro del mundo; } \\
\text { Lo fingido verdadero }\end{array}$ & $\begin{array}{l}\text { Calderón de la } \\
\text { Barca } \\
\text { Lope de Vega }\end{array}$ \\
\hline Motivo de la brevedad de la vida & El gran teatro del mundo & $\begin{array}{l}\text { Calderón de la } \\
\text { Barca }\end{array}$ \\
\hline Motivo de la fragilidad humana & El gran teatro del mundo & $\begin{array}{l}\text { Calderón de la } \\
\text { Barca }\end{array}$ \\
\hline $\begin{array}{l}\text { Motivo de la igualdad de todos } \\
\text { ante la muerte }\end{array}$ & El gran teatro del mundo & $\begin{array}{l}\text { Calderón de la } \\
\text { Barca }\end{array}$ \\
\hline
\end{tabular}

\section{Conclusión}

Los motivos clásicos empleados por los dramaturgos de los Siglos de Oro se pueden dividir en los motivos que proceden de la tradición literaria clásica y pueden ser mitológicos o no mitológicos y los motivos que en cuanto al argumento de la obra se construyen alrededor de un acontecimiento o un personaje que forma parte de la herencia clásica. Estos últimos no son tan frecuentes. La obra clásica que constituye la fuente por excelencia de los motivos dramáticos tanto en el Renacimiento como en el Barroco son las Metamorfosis 
de Ovidio y los motivos más frecuentes, sobre todo en el Barroco, son los mitológicos, ya que la mitología grecorromana expresa todas las experiencias, sentimientos, reflexiones, ideas y anhelos humanos fundamentales (Germ, 2001: 63). Con su mundo impresionante de imágenes ilusorias y temas y motivos de carácter dramático (ilusiones, desengaños, incertidumbre, dudas, temores, miedos...) las Metamorfosis llegan convertirse en una constante del Barroco y su imaginario

La influencia de Virgilio está presente sobre todo en la obra de Juan del Encina, no obstante, los autores considerados como fuentes clásicas en cuanto a los motivos empleados por los autores de los Siglos de Oro son numerosos y variados: los elegíacos romanos Propercio y Tibulo, el lírico Horacio, el dramaturgo Plauto, los filósofos estoicos Epicteto y Séneca, el novelista Apuleyo, el historiador Tácito y los dramaturgos griegos Esquilo y Aristófanes, así que podemos constatar que algunos motivos que perviven en los Siglos de Oro proceden de los orígenes mismos del teatro europeo. En cuanto a los géneros, los referentes clásicos de los motivos en las obras tratadas abarcan tanto los géneros literarios como no literarios: épica, lírica, drama, filosofía e historia.

Los motivos clásicos en el Renacimiento no son menos frecuentes que en el Barroco, ya que las obras del «padre» del teatro español Juan del Encina en su segunda etapa (italiana) están impregnadas de ellos. Sin embargo, no prevalecen los motivos mitológicos como en el Barroco, cuando, por ejemplo, Lope de Vega escribe el conjunto de las comedias mitológicas y Calderón de la Barca los autos sacramentales de tema mitológico, pero cabe señalar que son muy variados y proceden de diferentes autores y géneros literarios.

\section{Bibliografía}

Abellán, José Luis (1996): Historia del pensamiento español de Séneca a nuestros días. Madrid: Espasa Calpe.

Arróniz, Othón (1969): La influencia italiana en el nacimiento de la comedia española. Madrid: Gredos.

Cervantes, Miguel de (2004): El ingenioso bidalgo Don Quijote de la Mancha. Pérez López, José Luis (ed.). Madrid: Biblioteca IV centenario.

Cervantes, Miguel de (1984): Numancia. Marrast, Robert (ed.). Madrid: Cátedra. 
Egido, Aurora (ed.) et al. (2013): Speciale Cervantes. El robo que robaste. El universo de las citas y Miguel de Cervantes. Parole rubate. Rivista internazionale di studi sulla citazione. 8. Parma: Università degli studi di Parma. 〈http:// www.parolerubate.unipr.it/ fascicolo8_pdf/F8-14_montero_reguera_ robador.pdf> (15-08-2014).

Encina, Juan del (1998): Teatro completo. Pérez Priego, Miguel Angel (ed.). Madrid: Cátedra.

Fernández, Lucas (2002): Farsas y églogas I. Profanas. Valero Moreno, Juan Miguel (ed.). Salamanca: Universidad de Salamanca.

Germ, Tine (2001): Podobe antičnib bogov v likovni umetnosti od antike do izteka baroka. Ljubljana: DZS.

Highet, Gilbert (1985): The classical tradition: Greek and Roman influences on western literature. New York: Oxford University Press.

Rull Fernández, Enrique (2003): Autos sacramentales del siglo de oro. Madrid: Ediciones Libertarias.

Torres Naharro, Bartolomé de (2013): Teatro completo. Vélez-Sainz, Julio (ed.). Madrid: Cátedra.

Vicente, Gil (1996): Teatro castellano. Calderón, Manuel (ed.). Barcelona: Crítica.

Zamora Vicente, Alonso (1961): Lope de Vega. Su vida y su obra. Madrid: Gredos. Zimic, Stanislav (2003): Ensayos y notas sobre el teatro de Gil Vicente. MadridFrankfurt: Iberoamericana-Vervuert. 
Bojana Tomc

Diocesan Classical Gymnasium, Ljubljana

\section{Ancient Writers' Motifs in Spanish Golden Age Drama}

Keywords: ancient literature, Spanish literature, Golden Age, survival and reception, ancient motives

In Spanish Golden Age drama we come across all forms of the reception of ancient writers' motifs: explicit (direct quotation of an ancient author, where the quotation may be more or less complete, or a clear allusion to it), implicit (where there is no explicit mentioning of the ancient source, however certain ancient elements are mentioned such as persons, places, historical circumstances), bidden (where there is no clear hint about a literary intervention in Antiquity or an imitation of the literary excerpt or motif), as well as direct imitation (aemulatio) or adaptation (variatio). In the Renaissance and Baroque there are almost no motifs, which could not be taken over from Antiquity without a transformation or innovation. If there is a close correspondence to the ancient motif, it is generally sufficient simply to mention it or employ a side motif as an illustration of a similar situation without elaborating the motif further or weaving it more deeply into the supporting fabric of the dramatic work. The ancient authors who contribute the motifs are numerous and diverse: Vergil, the Roman elegists Propertius in Tibullus, the lyric poet Horace, the comedian Plautus, the stoic philosopher Seneca, the historian Tacitus, the novelist Apuleius, as well as Greek dramatist Aeschylus and stoic philosopher Epictetus. The genres, which are a source for the surviving ancient motifs in the Golden Age in the selected authors, include literary as well as not-literary forms: epic poetry, lyric, dramatics, philosophy and historiography. 
Bojana Tomc

Škofijska klasična gimnazija v Ljubljani

\section{Antični motivi v španski dramatiki zlatega veka}

Ključne besede: antična književnost, španska književnost, zlati vek, ohranitev in recepcija, antični motivi

V španski dramatiki zlatega veka zasledimo vse oblike recepcije antičnih motivov: odkrito (neposredno citiranje antičnega avtorja, pri čemer je lahko citat bolj ali manj popoln, ali jasna aluzija nanj), zastrto, kjer ni izrecne omembe antičnega vira, omenjajo pa se določeni antični elementi (osebe, kraji, zgodovinske okoliščine), in prikrito (ko ni nobenega jasnega namiga, da gre za literarni poseg $\mathrm{v}$ antiko oziroma imitacijo literarnega odlomka ali motiva), pri čemer gre lahko tudi že za naslednji stopnji, aemulatio ali variatio. Motivov, ki bi bili iz antike prevzeti brez transformacij oz. inovacij, v renesansi in baroku skoraj ni. Če popolnoma ustrezajo antičnemu motivnemu predhodniku, gre večinoma le za omembo ali uporabo stranskega motiva kot ilustracije podobne situacije brez poglobitve in močnejše vpetosti motiva $\mathrm{v}$ nosilno strukturo dramskega dela. Avtorji, iz katerih izvirajo antični motivi, so številni in raznovrstni: Vergilij, rimska elegika Propercij in Tibul, lirik Horacij, komediograf Plavt, stoiški filozof Seneka, delno tudi zgodovinar Tacit in rimski romanopisec Apulej, od grških piscev pa dramatik Ajshil in stoiški filozof Epiktet. Žanrsko dela, ki so vir za preživele antične motive v zlatem veku pri obravnavanih avtorjih, obsegajo tako literarne kot neliterarne zvrsti: epiko, liriko, dramatiko, filozofijo in zgodovinopisje. 